\title{
MODULASI DIGITAL MENGGUNAKAN MATLAB
}

\author{
Wahyu Pamungkas ${ }^{1}$ Anggun Fitrian Isnawati ${ }^{2}$ Adi Kurniawan $^{3}$ \\ 1,2,3 Akademi Teknik Telekomunikasi Sandhy Putra Purwokerto \\ Jl. D.I Panjaitan No. 128 Purwokerto, Telp: (0281) 641629 \\ Wahyu_pamungkas@hotmail.com, anggun_fitrian@yahoo.com, adikur46@yahoo.co.id
}

\begin{abstract}
ABSTRAK
Dalam sistem telekomunikasi penentuan sistem modulasi merupakan metode yang penting dalam proses pengiriman informasi dari pengirim ke penerima. Pada simulasi yang dikerjakan menggunakan modulasi QPSK (Quadrature Phase Shift Keying), 8-QAM (8-Quadrature Amplitude Modulation), 16-QAM (16-Quadrature Amplitude Modulation) yang menggunakan kanal AWGN (Additive White Gaussian Noise) dengan menggunakan software MATLAB. Pengerjaan simulasi bertujuan untuk mendeskripsikan bagaimana karakteristik bentuk gelombang dari tiap blok modulator, penambahan noise pada kanal AWGN dan demodulator. Apabila data informasi ditansmisikan melalalui kanal AWGN maka hasil data keluarannya menjadi kasar atau tercampur noise. Pengujian kinerja sistem modulasi yang digunakan yaitu metode BER (bit error ratio) melihat kesalahan bit dari hasil perbandingan bit sebelum dan sesudah dikirimkan dengan model simulasi Monte Carlo. Pengujian pada simulasi ini menggunakan data masukan sebanyak 10000 data simbol secara acak dan level Eb/No yang bervarisi untuk setiap modulasi yang digunakan. Hasil kinerja BER dengan nilai level Eb/No sebesar $1 \mathrm{~dB}$ dari sistem modulasi yang disimulasikan diperoleh nilai BER pada QPSK sebesar 0,0570, 8-QAM sebesar 0,1085 sedangkan 16-QAM sebesar 0,1582 dan maka kinerja modulasi yang terbaik adalah QPSK. Apabila Eb/No dinaikan menjadi $8 \mathrm{~dB}$ maka BER modulasi QPSK menjadi lebih kecil yaitu sebesar 0,00035, pada 8-QAM diperoleh BER sebesar 0,0076 sedangkan pada modulasi 16-QAM menjadi 0,0139.
\end{abstract}

Kata Kunci : QPSK, 8-QAM, 16-QAM, AWGN dan BER.

\begin{abstract}
In telecommunication systems, the determination of the modulation system is an important method in the process of sending information from transmitter to receiver. In the simulation that is done using QPSK modulation system (Quadrature Phase Shift Keying), 8-QAM (Quadrature Amplitude Modulation), 16-QAM (16-Quadrature Amplitude Modulation) that uses AWGN (Additive White Gaussian Noise) channel in the transmission system uses MATLAB software. The execution of the simulation is aimed to describe how the characteristics of the waveform of each block of the modulator, to add noise in the AWGN channel and demodulator. Performance of modulation system testing is used BER (bit error ratio) method. Looking of the faults of comparison bits results of before and after the transmitted bits by using Monte Carlo simulation model. Testing on this simulation using the input data as much as 10.000 data symbols randomly and the level of Eb/No that is various for each modulation used. Performance results BER with the level of Eb / No at $1 \mathrm{~dB}$ of the simulated system modulation on the BER values obtained for QPSK 0.0570, 8-QAM at 0.1085 while the 16-QAM at 0.1582 and then the performance of QPSK modulation is the best. If the Eb / No is increased to $8 \mathrm{~dB}$ then the becomes BER QPSK smaller modulation is equal to 0.00035, the 8-QAM BER obtained at 0.0076, while the 16-QAM modulation to be 0.0139.
\end{abstract}

Key Words : QPSK, 8-QAM, 16-QAM, AWGN and BER.

\section{A. PENDAHULUAN}

Perkembangan teknologi media

elektronik telah memberikan berbagai kemudahan

dalam penyebaran informasi serta peningkatan

kualitas dan kuantitas dalam penyampainnya, ditandai dengan penemuan-penemuan mutakhir di bidang ilmu pengetahuan dan teknologi seperti; radio, telegraph, telepon dan lainnya ${ }^{[8] \text {. }}$

Proses pentransmisian sebuah informasi melalui kanal maka tidak akan lepas dari kendala 
berupa timbulnya kesalahan. Salah satu parameter yang menentukan kualitas sistem modulasi digital adalah Bit Error Rate (BER). Untuk mengkaji lebih dalam karakteristik dan pengaruh BER terhadap kualitas pada modulasi digital maka digunakannya simulasi, salah satunya menggunakan software MATLAB.

\section{B. PERUMUSAN MASALAH}

Dari uraian di atas, maka dapat diketahui beberapa permasalahan yang dapat dikaji lebih lanjut, yaitu:

1. Bagaimana karakteristik bentuk gelombang modulasi digital khususnya pada Quatenary Phase Shift Keying (QPSK), 8 Quadrature Amplitude Modulation (8-QAM) dan 16 Quadrature Amplitude Modulation (16-QAM) yang melalui kanal AWGN.

2. Bagaimana pengaruh nilai $E b / N o$ terhadap Bit Error Ratio (BER) jenis modulasi QPSK, 8QAM dan 16-QAM yang melalui kanal AWGN.

\section{BATASAN MASALAH}

Adapun pembatasan masalah yang akan dibahas dan dikaji adalah sebagai berikut:

1. Modulasi digital yang digunakan QPSK, 8QAM dan 16-QAM.

2. Pentramisian sinyal modulasi menggunakan kanal AWGN (Additive White Gaussian Noise).

3. Pengukuran kinerja modulasi menggunakan nilai Bit Error Rate (BER) pada kanal AWGN (Additive White Gaussian Noise).

\section{TUJUAN PENULISAN}

Adapun maksud dari penulisan ini, yaitu:

1. Mengetahui bagaimana karakteristik bentuk gelombang modulasi digital khususnya pada QPSK, 8-QAM dan 16-QAM yang melalui kanal AWGN.

2. Mampu mengetahui pengaruh nilai Eb/No terhadap Bit Error Ratio (BER) jenis modulasi QPSK, 8-QAM dan 16-QAM yang menggunakan kanal AWGN.

\section{E. LANDASAN TEORI}

1. Sistem Komunikasi

Pengiriman data dalam sistem komunikasi dapat berupa dalam bentuk analog atau digital, apabila data yang dikirimkan berupa sinyal atau data analog maka diperlukan analog digital converter (ADC) yang berfungsi sebagai pengubah sinyal analog menjadi digital (1 dan 0). Source coding menerima data dalam bentuk digital dari ADC dan dikodekan kembali dalam bentuk sinyal digital, terdapat redudancy yang mempengaruhi dalam kecepatan transmisi data.

Channel encoder menerima keluaran data dari source encoder dan dipancarkan dalam bentuk data digital sesuai dengan panjang data pada channel encoder. Terjadinya pengurangan kelebihan data atau kompresi data proses ini disebut pengkodean sumber (source coding) yang mengakibatkan adanya error yang diakibatkan oleh noise atau interferensi yang dapat dideteksi atau dikoreksi saat diterima oleh penerima. Dalam pengiriman data yang menggunakan frekuensi 
tinggi pentransmisian simbol menggunakan frekuensi pembawa.

Modulator sistem trasmisi baseband dapat juga sebagai formator yang berfungsi sebagai penggambaran bentuk gelombang dari simbol data digital yang dikirimkan. Amplifier berfungsi sebagai penguat setelah data dimodulasikan. Media transmisi disebut juga kanal, di dalam kanal terdapat beberapa faktor yang mempengaruhi dalam pentransmisian sinyal yaitu noise, fading dan attenuasi ${ }^{[15]}$.

Data setelah melewati kanal maka akan di terima oleh Low Noise Amplifier (LPF) untuk pemfilteran noise dari data yang kemudian di terima oleh demodulator. Setelah data diubah kembali dalam bentuk digital maka akan diteruskan channel decoder dan source decoder penambahan redudancy sedemikian sehingga data yang diterima oleh penerima akan seperti data asli yang dikirimkan oleh pengirim.

Digital Analog Converter (DAC) digunakan untuk data digital apabila penerima membutuhkan sinyal analog. Langkah pertama dalam sistem transmisi sinyal baseband yaitu informasi diformat terlebih dahulu sehingga sinyal masukan ditampilkan dengan simbol-simbol digital. Bentuk gelombang pulsa ditetapkan untuk menampilkan simbol-simbol sesuai sistem modulasi yang digunakan pada tahap-tahap modulasi pulsa atau modulasi baseband. Tahaptahap pemrosesan sistem komunikasi digital dapat yang sudah dijabarkan pada gambar 1 :

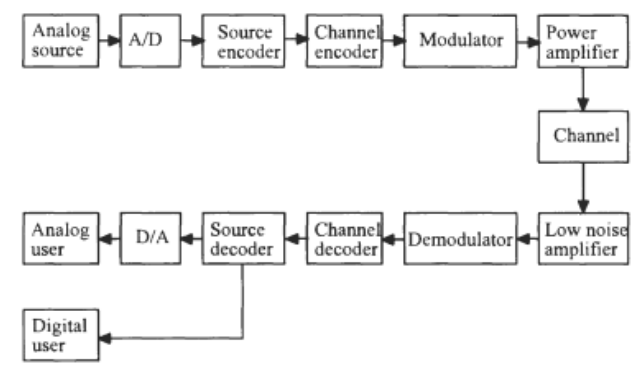

Gambar 1. Diagram Blok Sistem Komunikasi ${ }^{[16]}$.

\section{Kanal Komunikasi AWGN}

Dalam sistem pentransmisian sinyal membutuhkan media atau kanal untuk menyampaikan informasi dari transmiter ke receiver diantaranya adalah kanal Additive White Gaussian Noise (AWGN). Kanal AWGN adalah kanal yang ideal memiliki noise AWGN di dalamnya. Kanal dalam keadaan ideal yang berarti memiliki bandwidth yang tidak terbatas dan respon terhadap semua jenis frekuensi yang tidak mempengaruhi bentuk asli dari sinyal yang dikirim atau tidak mengalami distorsi ${ }^{[7]}$.

White noise pada proses AWGN bersifat power spectral density (PSD) yaitu memiliki spektrum rapat daya noise dianggap memiliki harga yang sama untuk setiap frekuensi yang ditransmisikan maka persamaan dari white noise ditunjukan pada persamaan $^{[9]}$ :

$$
S_{w}(f)=\frac{N_{0}}{2} \quad(\mathrm{~W} / \mathrm{Hz})
$$

Pola kemunculan noise dianggap terdistribusi Gaussian dengan nilai rata-rata (mean) adalah nol dan memiliki variansi yang tergantung dengan rapat daya yang diperkirakan dari noise tersebut. Persamaan nilai variansi AWGN ditunjukan pada persamaan: 


$$
\begin{array}{r}
f(x)=\frac{1}{\sqrt{2 \pi \sigma}} \exp \left(-\frac{x^{2}}{2 \sigma^{2}}\right) \\
\sigma_{i}^{2}=\frac{N_{0}}{2}, i=0.1
\end{array}
$$

Noise AWGN merupakan gangguan yang bersifat additive terhadap sinyal transmisi yang dapat dilihat dari karakteristik dari noise AWGN yaitu sinyal keluaran yang melalui kanal AWGN sama dengan sinyal asli di tambah dengan noise AWGN.

$$
Y(t)=n(t)+X(t)
$$

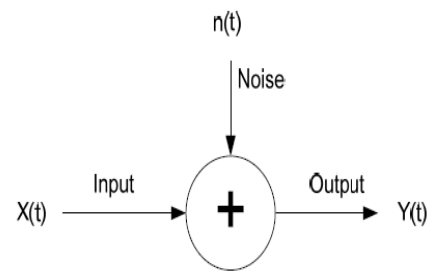

Gambar 2. Kanal AWGN ${ }^{[6]}$

\section{BER (Bit Error Rate)}

Cara mengukur kualitas sebuah sinyal salah satunya dapat dilihat dari hasil perumusan dari tiap kesalahan bit (bit Error) yang terjadi saat pentransmisian informasi dari sisi pengirim ke penerima dengan cara membandingkan data keluaran dengan data asli atau data masukan. Persamaan umum dari fungsi BER dapat dituliskan seperti pada persamaan berikut:

$$
\mathrm{BER}=\frac{\text { Jumlah bit error }}{\text { Jumlah total bit kirim }}
$$

\section{F. METODOLOGI PENELITIAN}

Pembuatan program simulasi modulasi digital yang bertujuan untuk mengetahui karakteristik bentuk gelombang dan pengaruh nilai parameter $\mathrm{E}_{\mathrm{b}} / \mathrm{N}_{0}$ terhadap bit error rate (BER). Karakteristik sinyal tersebut dilewatkan melalui kanal AWGN dengan menggunakan modulasi digital khususnya modulasi QPSK, 8-QAM dan 16-QAM. Pengerjaan program simulasi memerlukan sebuah hardware yaitu berupa personal computer (PC) atau laptop yang dilengkapi dengan software bahasa pemograman MATLAB.

Variabel dalam pembuatan program ini berupa parameter yang digunakan pada perhitungan BER (bit error rate) adalah $\mathrm{E}_{\mathrm{b}} / \mathrm{N}_{0}$.

Rancangan dalam proses peñyelesaian simulasi modulasi digital Quatenary Phase Shift Keying (QPSK) , 8-Quadrature Amplitude Modulation (8QAM) dan 16-Quadrature Amplitude Modulation (16-QAM) dengan menggunakan perangkat lunak MATLAB.

1. Peraancangan Simulasi Pembangkitan Sinyal

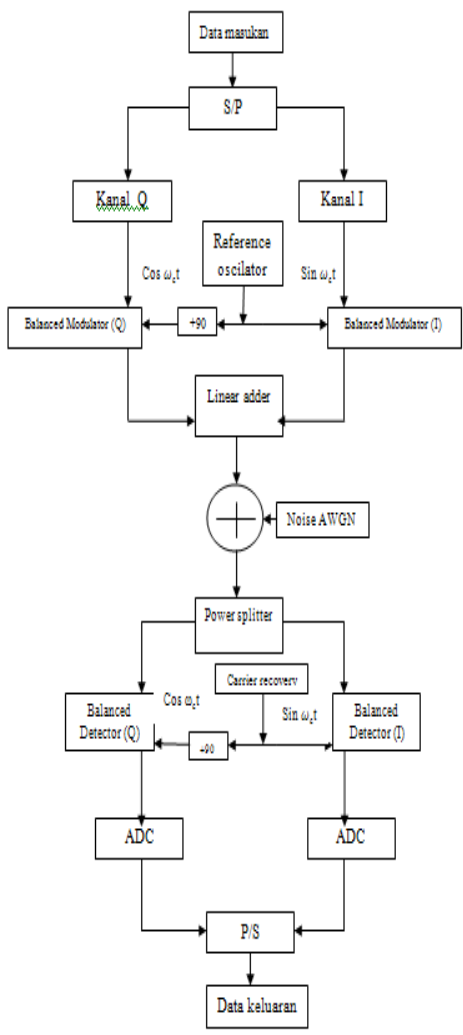

Gambar 3. Diagram Blok Simulasi Pembangkitan Sinyal 
2. Perancangan Simulasi Perhitungan BER (Bit Error Rate)

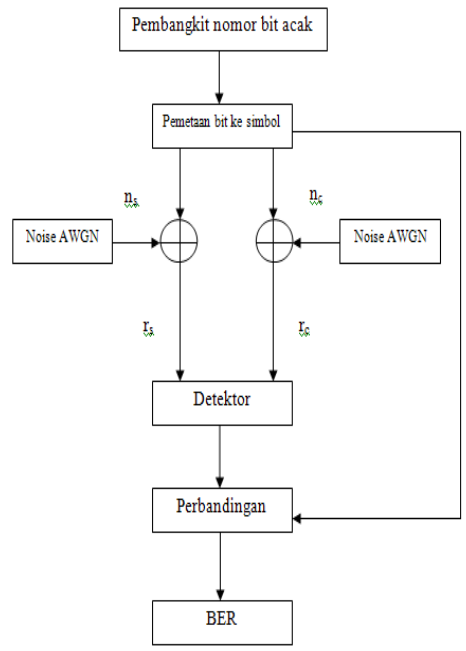

Gambar 4. Diagram Blok Perhitungan BER

Menggunakan Monte Carlo

\section{G. HASIL DAN PEMBAHASAN}

\section{Hasil dan Analisa Blok Data Masukan}

Pada pengujian simulasi menghasilkan data masukan dengan nilai bit 100100100011 untuk QPSK, 110110011101 untuk 8-QAM dan 1101111110100001 untuk 16-QAM.

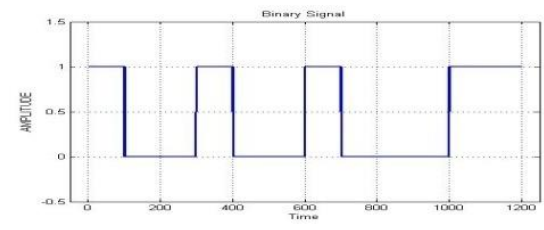

Gambar 5. Sinyal Digital QPSK

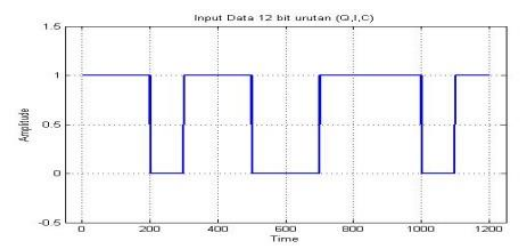

Gambar 6. Sinyal Digital 8-QAM

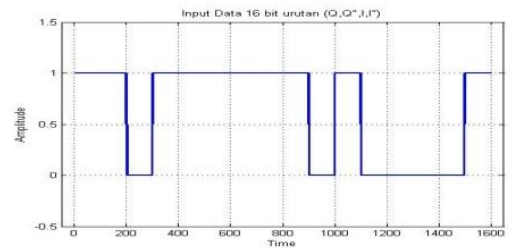

Gambar 7. Sinyal Digital 16-QAM

\section{Hasil dan Analisa Data Keluaran}

Data keluaran merupakan data hasil keluaran dari $\mathrm{P} / \mathrm{S}$ yang merupakan penggabungan dua sekuens yaitu dari kanal I dan kanal Q yang diurutkan menjadi data tunggal secara serial.

Tabel 1. Hasil Data Masukan dan Data Keluaran

\begin{tabular}{|c|c|c|c|}
\hline No & Jenis Modulasi & Data Masukan & Data Keluaran \\
\hline 1 & QPSK & 100100100011 & 100100100011 \\
\hline 2 & 8-QAM & 110110011101 & 110110011101 \\
\hline 3 & $16-Q A M$ & 1101111110100001 & 1101111110100001 \\
\hline
\end{tabular}

\section{Hasil dan Analisa Diagram Konstelasi}

\section{Bentuk diagram konstelasi dari Quadrature Phase Shift Keying (QPSK)} terdapat 4 titik simbol dimana untuk satu titik mewakili 2 bit data yaitu 00,01,10, dan 11 yang memiliki beda phasa sebesar $90^{\circ}$.

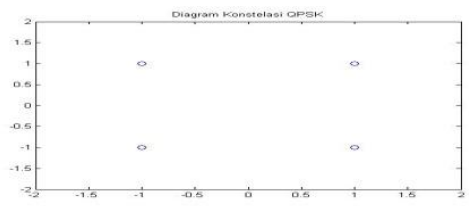

Gambar 8. Diagram Konstelasi QPSK

Pada 8-QAM (8-Quadrature Amplitude modulation) Bentuk diagram konstelasi terdapat 8 titik simbol dimana untuk satu titik mewakili 3 bit data. 


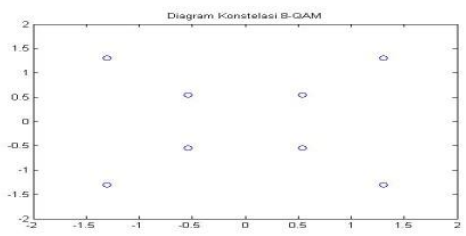

Gambar 9. Bentuk Diagram Konstelasi 8-QAM

Bentuk diagram konstelasi dari 16-QAM terdapat 16 titik simbol dimana untuk satu titik mewakili 4 bit data.

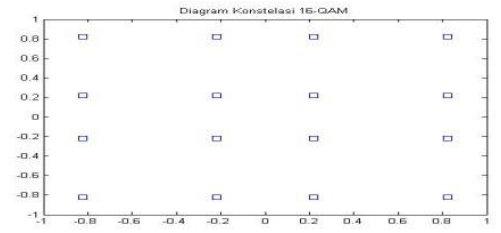

Gambar 10. Bentuk Konstelasi Diagram 16-QAM

\section{A. Pengujian Kinerja BER}

Pengujian simulasi perhitungan QPSK menggunakan variasi level nilai Eb/No dengan nilai 0 sampai dengan 9 dengan rentang $1 \mathrm{~dB}$.

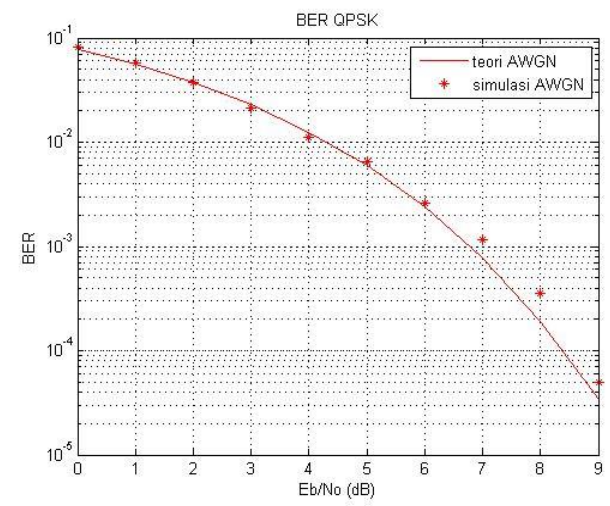

Gambar 11. Grafik Perbandingan Eb/No terhadap BER QPSK

Data masukan berupa variabel acak dengan jumlah $\mathrm{N}=10000$ data simbol, rentang pola kemunculan simbol dibagi menjadi empat interval yaitu $(0,0,25),(0,25,0,5),(0,5,0,75)$, dan $(0,75$,
1,0), untuk setiap sub interval melambangkan simbol dengan 00, 01, 11, dan 10.

Pengujian simulasi mengunakan variasi level nilai Eb/No mulai nilai 0 sampai 10 dengan peningkatan level 1dB. Data masukan berupa variabel acak dengan jumlah $\mathrm{N}=10000$ data simbol, dengan asumsi setiap simbol memiliki energi $1 \mathrm{~dB}$ dan energi rata-ratanya $\left(\mathrm{E}_{\mathrm{avb}}\right)$ sebesar $6 \mathrm{~dB}$.

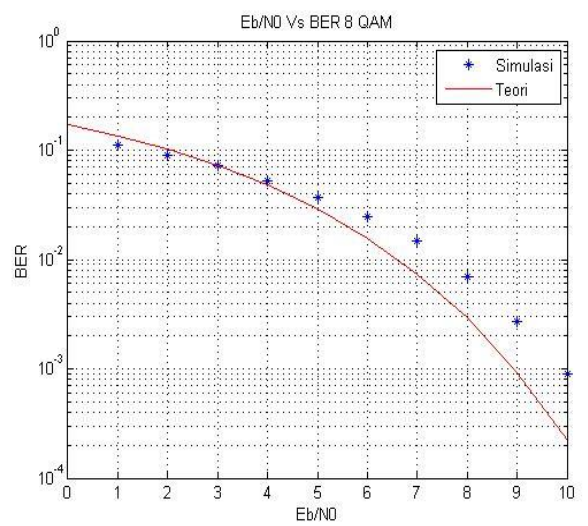

Gambar 12. Grafik Perbandingan Eb/No terhadap BER 8-QAM

Pengujian simulasi mengunakan variasi nilai Eb/No mulai nilai 0 sampai 12 dengan peningkatan level $1 \mathrm{~dB}$.

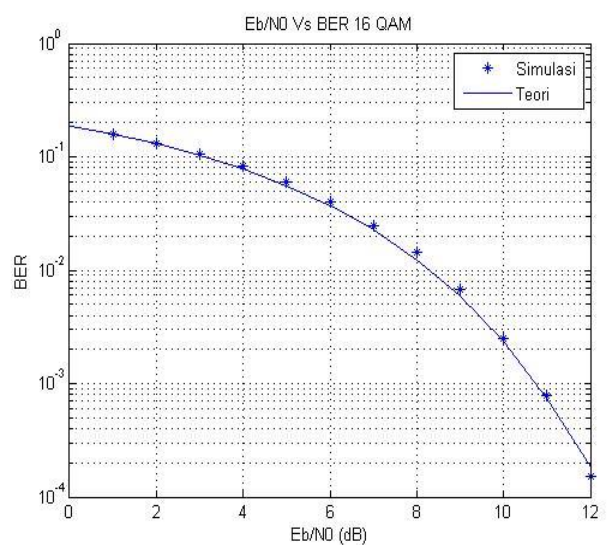

Gambar 13. Grafik Perbandingan Eb/No terhadap BER 16-QAM 
Data masukan berupa variabel acak dengan jumlah $\mathrm{N}=10000$ data simbol, dengan asumsi setiap simbol memiliki energi $1 \mathrm{~dB}$ dan asumsi energi rata-ratanya $\left(\mathrm{E}_{\mathrm{avb}}\right)$ sebesar $10 \mathrm{~dB}$.

\section{B. Perbandingan Kinerja Sistem Modulasi}

Hasil perbandingan kinerja dari modulasi QPSK, 8-QAM dan 16-QAM dilihat dari perbandingan Eb/No dengan nilai yang sama terhadap BER dari setiap modulasinya. Contoh nilai Eb/No yang diambil adalah $8 \mathrm{~dB}$ maka diperoleh nilai BER pada modulasi QPSK sebesar 0,00035, untuk modulasi 8-QAM diperoleh BER sebesar 0,0076 sedangkan pada modulasi 16-QAM diperoleh BER sebesar 0,0139.

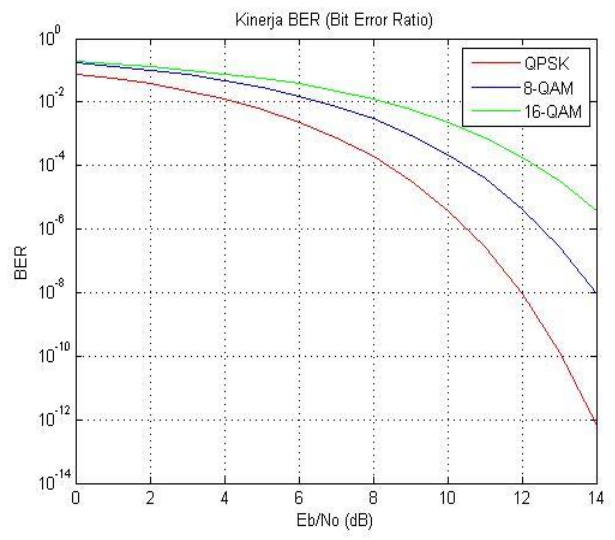

Gambar 14. Kinerja BER

Berdasarkan dari hasil simulasi dan grafik pada gambar 4.46 maka diketahui perbandingan nilai BER dari setiap modulasi dengan level Eb/No yang sama bahwa pada modulasi QPSK memiliki nilai BER lebih kecil daripada modulasi 8-QAM dan 16-QAM. Pemilihan modulasi untuk pentransmisian informasi pada sistem komunikasi apabila dilihat dari kinerja BER-nya maka lebih optimum menggunakan QPSK.

\section{H. KESIMPULAN}

Berdasarkan hasil analisis yang telah dilakukan, maka dapat diperoleh kesimpulan:

1. Dalam pembangkitan gelombang tidak dapat mengetahui secara langsung nilai BER-nya dan diasumsikan tidak adanya error bit yang ditransmisikan, karena dalam pembangkitan gelombang hanya mendeskripsikan bentuk gelombang secara umum.

2. Hasil perbandingan antara BER simulasi dengan perhitungan secara teoritis atau menggunakan rumus memiliki nilai yang tidak berbeda jauh atau hampir sama. Apabila hasil simulasi dipetakan ke dalam grafik dicontohkan pada modulasi 8-QAM dengan Eb/No level 1 $\mathrm{dB}$ dihasilkan nilai BER pada simulasi lebih baik yaitu sebesar 0,1085 apabila dibandingkan dengan hasil perhitungan rumus yang diperoleh sebesar 0,1105 , sedangkan pada titik level $7 \mathrm{~dB}$ pada simulasi diperoleh BER yang kurang baik yaitu sebesar 0,0132 dibandingkan dengan perhitungan secara teoritis atau menggunakan rumus yaitu sebesar 0,1283.

3. Berdasarkan dari hasil simulasi nilai BER pada modulasi QPSK dengan nilai Eb/No $1 \mathrm{~dB}$ yaitu 0,0570 sedangkan dengan nilai $9 \mathrm{~dB}$ diperoleh nilai BER sebesar 0,00005. Pada modulasi 8QAM dengan Eb/No 1 dB maka BER bernilai 0,1085 apabila pentransmisian dengan $9 \mathrm{~dB}$ diperoleh nilai BER sebesar 0,0033. Sedangkan pada modulasi 16-QAM dengan level $1 \mathrm{~dB}$ diperoleh nilai BER 0,1582 apabila 
pentransmisian menggunakan $9 \mathrm{~dB}$ diperoleh BER 0,0065, maka dari hasil simulasi tersebut bahwa semakin besar level Eb/No yang digunakan maka nilai BER (bit error rate) akan semakin kecil.

4. Semakin tinggi nilai M_ary maka semakin banyak jumlah bit yang mewakili dalam satu simbol. Banyaknya jumlah bit adalah $\log _{2}$ dari besar nilai $\mathrm{M}$ atau kemungkinan simbol yang terbentuk. Maka apabila 1 simbol salah maka sebanyak bit yang mewakili dianggap salah walaupun yang salah hanya satu bit dari bagian simbol tersebut. Hasil dari simulasi penstransmisian menggunakan level Eb/No yang sama untuk modulasi QPSK, 8-QAM dan 16-QAM yaitu sebesar $8 \mathrm{~dB}$ dihasilkan nilai BER pada modulasi QPSK sebesar 0,0035, pada modulasi 8-QAM 0.0076 sedangkan pada modulasi 16-QAM sebesar 0,0139. Maka dari hasil simulasi bahwa semakin tinggi tingkatan M_ary yang digunakan, dengan nilai level Eb/No yang sama maka semakin besar nilai kesalahan bit atau BER yang dihasilkan.

\section{DAFTAR PUSTAKA}

1. Aminuddin, J. (2008). Dasar-Dasar Fisika Komputasi Menggunakan Matlab. Yogyakarta: Gava Media.

2. Blanchet, G., \& Charbit, M. (2006). Digital Signal and Image Prosesing Using MATLAB. London: ISTE Ltd.

3. Cahyo, W. N. (2008). Pendekatan Simulasi Monte Carlo untuk Pemilihan Alternatif dengan Decision Tree pada Niali Outcome yang Probabilistik. Teknik Industri Fakultas Teknologi Industri Universtias Islam Indonesia Yogyakarta , 7.

4. Chaparo, L. (2010). Signal and System Using MATLAB. Burlington: Elsevier.

5. Faridah, L., \& Pratiarso, A. (2009). Pembuatan Modul Praktikum Teknik Modulasi Digital 8-QAM, 16-QAM dan 64QAM Menggunakan Software. Teknik Telekomunikasi Fakultas Politeknik Elektronika Negeri Surabaya, 6.

6. G.Proakis, J., \& Salehi, M. (1998). Contemporary Communication Using MATLAB . Boston: PWS Publishing Company.

7. Hapsara, A. K., \& Susanto, I. (2007, 2 4). Kinerja Modulasi Digital dengan Metode PSK (Phase Shift Keying). Teknik Elektro Fakultas Teknik Universitas Diponegoro, p. 8.

8. Harada, H., \& Prasad, R. (2003). Simulation and Software Radio for Mobile Communication. Artech House Universal Personal Communications: Canton Street Norwood.

9. Haykin, S. (2000). Communication System.4th ed. Library of Congress Cataloging-inPublication Data. New york.

10. http://www.complextoreal.com. (n.d.). Retrieved $10 \quad 14, \quad 2011$, from http://cp.literature.agilent.com/litweb/pdf/596 5-7160E.pdf

11. M.Hussain, Z., Z.Sadik, A., \& O'shea, P. (2011). Digital Signal Processing And 
Introduction with MATLAB and ApPlication. New York: Springer Heidelberg Dordrecht London.

12. Moh.Nazir, P. (2005). Metode Penelitian. Bogor: Ghalia Indonesia.

13. Novia, P., \& Pratiarso, A. (2010). Pembuatan Modul Praktikum Teknik Modulasi Digital FSK, BPSK dan QPSK Menggunakan Software. Teknik Telekomunikasi Fakultas Politeknik Elektronika Negeri Surabaya, 7.

14. Sklar, B. (2006). Digital Communications Fundamentals and Applications Second Edition. New Jersey: Prentice Hall PTR.

15. Stallings, W. (2007). Komunikasi \& Jaringan Nirkabel jilid 2 . jakarta: Erlangga.

16. Xiong, F. (2000). Digital Modulation Technique. Canton Street Norwood: Artech House Telecomunication Library. 